\title{
ACTIVE LEARNING TECHNOLOGIES IN DISTANCE EDUCATION OF GIFTED STUDENTS
}

\author{
Dr. Abakumova Irina, Corresponding Member of Russian academy of education, Don State Technical University, \\ Rostov-on-Don, Russian Federation \\ E-mail: abakira@mail.ru \\ Dr. Bakaeva Irina, Southern Federal University, Rostov-on-Don, Russian Federation \\ E-mail: iabakaeva@sfedu.ru \\ Dr. Grishina Anastasia, Don State Technical University, Rostov-on-Don, Russian Federation. \\ E-mail: avgrishina.sfedu@gmail.com \\ Dr. Dyakova Elena, Rostov State Transport University, Rostov-on-Don, Russian Federation \\ E-mail: evdyakova.rgups@gmail.com
}

\section{A R T I C L E I N F O}

Original Research

Received: February, 14.2019.

Revised: March, 22.2019.

Accepted: April, 06.2019.

doi:10.5937/ijcrsee1901085A

UDK

37.018 .43

$159.928-057.875$

Keywords:

distance education,

sense formation,

distance technologies,

intellectually gifted,

independent activity,

developing potential.

\begin{abstract}
A B S T R A C T
The article reveals the notion of distance education, meaning formation, meaningful technologies. The modern concept of psychological and pedagogical support of talent is associated with the concept of the child's abilities disclosure in education. Discussion about the developing potential of distance education, where, on the one hand, the student's development potential is flattened, compressed and translated into "one-dimensional space" in the process of education; on the other hand, there is a whole range of opportunities to initiate independent activity of students, to include mechanisms of cognitive and personal development of a modern student. The psychological bases of active learning technologies in distance education of gifted students are described. The author's classification of interactive learning technologies using remote technologies is considered, where each technology finds several concrete embodiments. The results of an experimental study of gifted students' independent activity initiation in distance education are presented.
\end{abstract}

\section{INTRODUCTION}

In modern psychological and pedagogical studies, the topic of informatization, high technologies, computers, Internet in the life of society is actively discussed. Various interactive resources, media, distance and mass online courses, which are used to organize the training, are widely distributed in the educational system. Online resources are introduced into the traditional educational process as tools for organizing independent activities of students, filling the academic discipline with new and up-to-date information, implement-

Corresponding Author

Dr. Grishina A., Don State Technical University, Rostov-on-Don, Russian Federation.

E-mail: avgrishina.sfedu@gmail.com

\section{c) (i) $\Theta$}

This work is licensed under a Creative Commons Attribution - NonCommercial - NoDerivs 4.0. The article is published with Open Access at www.ijcrsee.com (c) 2019 IJCRSEE. All rights reserved.

ing automated or centralized control. In other systems, distance education (DE) completely replaces the traditional one.

ICDE studies show that the current trend is the expansion and deepening of the open and distance education quality throughout the world. Priority tasks are:

- creation of favorable structures for open education (OE) at all levels;

- stimulating the use of Open Educational Resources (OER) - Open educational resources - publicly funded educational resources;

- development of international structures for the qualifications confirmation;

- adoption of the quality standards, recommendations and assessments for open, online and distance learning, to improve the quality of distance education, and to develop innovative approaches to the learning outcomes evaluation (Ozhgibesova N. and Chelyadinova O.,2014).

Accordingly, the psychological and methodological foundations of interactive 
education with the use of technical means or by means of only electronic technologies are at the level of scientific discussion. They meet with heated discussion both in scientific circles and in the practice of the teacher's activity. The methodology lags behind the implementation practices.

The analysis of Russian and foreign research allows us to identify the main problem points in the application of distance technologies.

In the works of A. A. Andreev and the Concept of the creation and development of distance education unified system in the Russian Federation distance education is understood as "a set of educational services provided to wide sections of the population in the country and abroad with the help of a specialized information and educational environment based on the means for the exchange of educational information at a distance (satellite television, radio, computer communications, etc.) "(Bakaeva I., 2016). Distance education involves interactive interaction between the learner and the cumulative subject(teachers plus other students) of the information environment, in which the environment becomes both an object of intellectual activity and its (the environment plus the learner) subject.

Distance learning is understood as learning "provided by the use of educational technologies set, in which the purposeful indirect or not completely mediated interaction between the learner and the teacher is carried out irrespective of their location and distribution in time on the basis of pedagogically organized information technologies, primarily with the use of telecommunications means" (Decree of the Russian Federation State Committee of Higher Education, 1995).

Russian researchers, L. Alkova, O. Babanskaya, I. L. Vasilyeva, M. B. Lebedeva is considering distance interactive learning technologies as effective methods for developing students' independent activities with the goal of forming various educational and professional competences (Lebedeva M. B., 2010). At the same time V. V. Davydov, N. B. Kocharyan differentiate the various problems and difficulties in introducing distance learning into mass practice, which is associated with economic difficulties, the unavailability of teachers, low student motivation, and psychological factors, like the shortcomings in the development of modern students' speech, "flattened" perception, and as a result narrow thinking, not generates broad alternatives, which contradicts the developmental nature of education. Some adherents of traditional learning in face-to-face discussions often argue that distance education further exacerbates the immersion of modern students in the virtual world, adversely affects their cognitive resources development, makes them "slaves" of technology.

G. A. Reznik, Y. S. Ponomarenko, O. V. Lyshchik in their studies emphasize that the introduction of distance and mass electronic technologies in the Russian education is hampered by the inadequate elaboration of the scientific-methodological and normative bases of distance education in educational institutions, the lack of psychological and technological readiness of specialists, the development and implementation of these technologies, the insufficient technical equipment of the educational process (Reznik G. A., Ponomarenko Yu. S. and Lyshchik O. V., 2016).

T. V. Gromova, Y. V. Semochkina also highlight the importance of methodological and methodological study of on-line and distance education in modern systems. They study the features of active methods of training in DE: case-method, brainstorming, business games (Gromova T. V. and Semochkina Yu. V., 2016).

The possibilities and reserves of using massive open online courses as a new, even more recent model of distance education in the educational space of higher education are being studied in the works of E. A. Shuklina (Shuklina E. A., 2016). The author emphasizes the pent-up demand for young people online education.

Author's positions allow us to conclude that distance and other electronic technologies are the vital result of the society informatization development. At the same time, e-learning opens up new horizons for pedagogical practice, allows expanding the resources, technologies and methods of teaching. New technologies put education itself to a new level, providing continuous education throughout life, and educational organizations in the role of innovation centers. Distance technologies change both the philosophy and the methodology of education, when education acquires a nonlinear model, where the subjectsubject relationship of the teacher and student comes to the fore in the process organization, and organizational structures become auxiliary tools. The training process itself changes from strictly regulated to flexible, the speed of training depends only on its subjects. The program and content of training can be multiplied a hundred times in geometric progression by 
attracting all the new resources and wiki technologies in accordance with the student's requests and opportunities.

In the modern practice of identifying and developing children's talent, the most important question is the pedagogical and psychological support of the child's development individual trajectory. It is not always possible to implement by means of education institutions or even the city. Often we can use the educational resources necessary for the promotion and development of the child from the Internet. Mass open online courses, online competitions, contests, online communities contribute to the development of various competencies and self-development of a gifted student.

Euna Park, Hae-Deok Song, Ah Jeong Hong explore the impact of new trends in education and technology, in particular the use of social networks in the process of motivating students to learn (Park E., Song H. D., Hong A. J., 2018).

The question of the distance technologies developing potential, their application with the goal of transforming the student's mental cognitive processes arises in psychological science.

Thus, the development of the psychological foundations and methods of DE are reflected in modern studies. There is a search for effective technologies of implementing distance education for students and youth; development of self-educational competences of students; the use of information and communication technologies to implement various control options, such as the rating system, evaluation systems. Practitioners describe the use of various educational resources, such as a wiki portal, electronic simulators; issues of networking in the educational environment. Concerning distance education of schoolchildren, most of the works cover the distance education of persons with disabilities, the disclosure of various electronic tools functionality.

Pedagogical psychology is in difficulty with the task of developing the learning motivation, developing skills and motivations for independent learning activities. Modern research, revealing the new didactic, psychological and pedagogical foundations of modern education, are reflected in the works of I. A. Abakumova, D. A. Leontiev, I. A. Rudakova, M.A. Friesen, who describe the technological components of learning activity organization in general and independent cognitive activity in particular through a deep psychological analysis of the students meaning (Aba- kumova I. V. et al, 2014). In Russian psychology, the development of the meanings theory, which is currently studying the technology of students sense-formation processes initiation, triggering other mechanisms for motivating self-educational activity: the initiation of reflexive abilities is described by E. V. Belova, studying the technology of directed meanings in learning, studies L. Ts. Kagermazova, the influence of students' meanings is described by I. A. Nesterenko.

Ideas of personalized, semantic learning are an important milestone of modern psychological and pedagogical thought. This approach, built on the theory of meaning relative to learning activity, develops in the integrative model of sense formation in the educational process developed by I. V. Abakumova (Abakumova I. V. et al, 2014). In this theory, the prerequisites for the personal development of students, which create conditions for more complete self-regulation, are considered as fundamental. Namely, the personal component is indispensable in independent activity. Sense formation is understood by I. V. Abakumova as "the development of individual meanings of the participants in pedagogical interaction: their enrichment and their multidimensionality acquisition through interaction with the personal senses of other subjects of pedagogical interaction, with pedagogical meanings and culture texts" (Abakumova I. V. et al, 2014).

In the concept of guided independent learning, which is based on the reorientation of the current learning process from an extensive to an intensive basis (I. V. Abakumova, V. T. Fomenko) (Abakumova I. V. et al, 2014, p. 37). Independent activity of students in it is an important psychological link of selfdevelopment, at each stage of which we observe the formation of knowledge volume and skills for solving cognitive tasks and progressing through the levels of intellectual activity. Determining importance in the independent work effectiveness has a motivation - external, internal and procedural or educational (Abakumova I. V. et al, 2014, p.17). Accordingly, when organizing the independent activity of students, the main goal is personal development, self-realization, creative development, and the application of self-managed learning technologies contributes to this in full.

The majority of foreign researchers of the beginning of the XXI century connect the problem of students' independent activity with the technologies development. They are called in different ways: distance learning, elearning, flexible training, etc. In the English 
psychological and pedagogical literature, the questions of organizing independent activity are studied in Oxford, the founder of distance university education, where, as described by Ashwin P., Archer I. W, Beck R. J., independent work is built on the basis of methodological materials with the participation of tutors. The University's Education Committee determines the aim of the tutor to develop the individual abilities of the student to master the depth of the subject area, and to work with growing confidence in their abilities.

Distance learning is recognized as an evolving element of education throughout the world. M. A. Uddin in his works cites facts that only in the US 6.7 million students were trained online in 2011, which amounted to $32 \%$ of the total set in higher education (Uddin M. A., 2013).

The most discussed issue is selecting the content of independent learning. M. Ally emphasizes the importance of using a multi-approach in the design of distance learning materials. He believes that it is necessary to use a combination of theories, thereby developing distance learning materials. In addition, the author points to the continuity of the science development, new materials of which must be used in the online materials development.

In modern foreign studies, issues of the effectiveness of independent activity are being actively considered. J. L. Moore studies the student's self-regulation characteristics from the social cognitive point of view. The author defines the student's autonomy as the degree to which the student determines the goals, the learning process and evaluates the decisions. He believes that the greatest success in the distance learning courses will be the most self-organized and independent students. J. L. Howland, J. L. Moore note the importance of the issues of independent learning activities research in the context of online learning; lead positive correlations of self-organization with positive academic results and the safety of the contingent of students, as well as their satisfaction with the program. Kelsey Hood Cattaneo points out that there are difficulties in identifying certain didactic categories of active learning pedagogy, which are based on insufficient knowledge of teaching methods (Hood Cattaneo, K., 2017).

Y. Vovides, S. Sanchez-Alonso, V. Mitropoulou, G. Nickmans point to the active interaction between the teacher and pupils in distance education, which increases the emotional participation of pupils in learning and increases students' self-motivation, self- regulation and self-management. The authors insist on creating an emotionally supportive learning environment that promotes cognitive development of students and develops critical thinking (Silchenko L. and Zubova T., 2017). J. Oomen-Early, L. Murphy consider that distance learning technology promotes selfactualization of both students and teachers, arguing that distance learning simultaneously facilitates student independence and control, while contributing to the satisfaction of adults self-actualization needs.

Thus, the search for ways and methods of development and initiation of independent cognitive activity is key in the current educational situation in the light of the federal state educational standards introduction and education modernization in Russia.

In distance education as one of the technologies for initiating independent activity, researchers find distinctive developmental markers, which are fixed in this form. Distance education assumes an interaction between the learner and the cumulative (teachers plus other students) the subject of the information environment, in which the environment becomes simultaneously the subject of intellectual activity and its (the environment plus the learner) subject. The psychological grounds for the development of independent students activity in the distance education system are revealed: first, in distance education, the environment acts as a means of expanding the consciousness and memory of a person and becomes a form of individual consciousness being and memory; secondly, the processes occurring within the learning system are represented in the outside and vice versa; thirdly, the very process of education is a model of intellectual activity in general, it can be easily seen that it is structured and allows you to isolate, objectify and study its various functions; fourth, the "impersonal" and "formalized" process of distance learning, in deep structure carries the developing potential of a very wide spectrum of action: the formation of productive, creative functions of thinking, the growth of intellectual abilities, the formation of the operational style of thinking, formed the motivational structure of the personality, the development of self-organization skills, personal development through the development of character; fifth, the competent use of all pedagogical influence factors is a factor in the identification and intensification of the motivational mechanisms of the adolescent's personality; sixthly, the use of specially developed technologies for the independent activity initiation will help 
to increase the educational and cognitive motivation through the initiation of various types of activity: involuntary, voluntary and postoperative, while the various personal spheres of the student develop.

Our author's approach consists in examining the technologies of distance education in the context of their sense-building potential (the theory of sense formation by I. V. Abakumova) (Abakumova I. V. et al, 2014); and also the description of the possibilities of using each technology type in the context of interactive education, taking into account its meaning-creating role (Bakaeva I., 2016).

Under the technologies of initiating the independent activity of students, we mean the system of teachers and students activity in the educational process, built with the aim of developing students' independent activity in accordance with the principles of the cognitive independence development and using a certain set of methods (in particular, distance education technology).

The activity of the teacher in terms of developing specific technologies that cause the students' educational and cognitive motivation should be based on the system of activity, through the development of different activity types. We propose a scheme for initiating independent activity using various technologies that initiate certain types of student's cognitive activity.

So the independent activity initiation through various technologies, for example, information transfer technologies or developing technologies determine the impact on various information perception channels, which triggers the initiation of involuntary cognitive activity. Interactive technologies such as brainstorming, corporate interaction, game modeling, in addition to teaching and developing effect, cause personal transformation, personal qualities development.

The use of technologies for students' sense formation, such as creative and semantic tasks, problem training, discussion methods that focus on the value sphere, involves the initiation of higher motivation levels related to the personal students senses, and, therefore, learning and knowledge are appropriated by the students as necessary for themselves, and there is activation of post-cognitive activity.

In distance education control plays an important role as an integral component of managed learning. Self-monitoring and selfevaluation of students develop through automated regular monitoring, and, thus, volun- tary cognitive activity is activated.

The use of information technology in distance education implements other psychological mechanisms. Thus, an increase in the proportion of independent work and a decrease in the role of pedagogical influence makes it possible to make this impact more directional. The teacher in his communication with the students sets an indicative basis for the action, and then the student himself justifies the scheme of activity. The student increases the proportion of self-esteem when he becomes an active figure in his own educational process.

Different level of students knowledge and skills at the entrance to the learning process does not interfere with the learning process, but contributes to a more individualized accompaniment by the teacher of the whole process, when each student crosses new material at his own pace and through his system of tasks. That is, each student takes possession of the material in different degrees and different sides of knowledge, this increases the efficiency and objectivity of monitoring and evaluation.

In distance learning, taking into account the model of translational learning and the use of all available telecommunication channels, the teacher-learner's communication is more intimate, since it is more accessible in time and space, and secondly more individualized and personified. That also contributes to the initiation of cognitive activity of students. The development of students' creative abilities, using creative and semantic tasks is an important quality of distance education.

We propose the author's classification of technologies for initiation of independent activity in distance education. In accordance with the principle of independence and creative thinking gradation; in the classification we can see the interconnectedness and unity of different types of tasks in the learning process, we highlight development technologies, interactive technologies, information transfer technologies, and the technologies for initiating meaning formation. All these groups have within themselves a cluster of technologies that can be used with the help of distance education in various electronic shells (in particular, in Moodle technology).

These technologies use various psychological mechanisms to attract cognitive interest of students, intensify cognitive processes, develop skills of students independent activity, as a result, increase the motivation for independent activity and learning in general. Following I. V. Abakumova, P. N. Ermakov, 
V. M. Antipova we classify technologies on various grounds: the degree of their developmental orientation, the degree of interactivity, the methods of information transfer and the meaning-creating potential (Abakumova I. V. et al, 2014).

In our study we distinguish such technologies as developing technologies, which include technologies for working with text, project technology, case studies. These technologies help students learn the skills of selfextracting information, while actively using the cognitive structures of memory, thinking, imagination. These technologies are designed for the intensive development of the personality in terms of the organization of the process in conjunction with other students and in independent activity.

The next class of technologies are interactive technologies as technologies that imply interaction, which are based on the principles of interaction, activity of trainees, reliance on group experience, mandatory feedback. In the context of distance learning, these technologies involve the interaction not only of the teacher and student, but also of students among themselves, as well as of the learner with the teaching medium. These technologies include corporate interaction, brainstorming, decision tree as an interactive technology of collective-group interaction; game simulation and incident method as interactive situational modeling technologies; discussion as an interactive technology for the development of discussion issues.

An important role in the initiation of the students self-educational activity is also in the properly selected and organized technologies of information transfer. In distance education the role of communication is very important. Since there is no moment of psychological contact between the teacher and the student, the structure of perception and understanding of the material changes, the means of perception from the auditory ones change dramatically - in the traditional education, the visual - in the distance learning. To use information more effectively and its role in learning, it is necessary to use various channels of information perception when teaching. In distance education, this is possible with the help of audio-visual information technologies. Where computer technologies (interactive textbooks and lectures, audio and video materials, recordings of lectures and educational films, etc.) appear in all their diversity, but also the more traditional technology of teaching through work with the curriculum also remains relevant and important in terms of developing self-educational competence.

As a separate group, we sing out the technologies of students' sense formation initiation as the main group of technologists that influence the deeper value-semantic structures of students and the development of their motivation for independent cognitive activity. These are technologies that are oriented not at "the steady mastering of knowledge", not on "active thinking", or on "creative activity", but directly on the sense-formation of students, accompanied by more or less expressed states of experience. With regard to distance learning, the most clearly represented from this class are technologies of creative and semantic tasks and problem training.

Thus, the use of different groups of technologies, oriented to different areas of mental development, which in fact are different in form and content, we use human development resources. Sense-forming potential of technologies allows to deduce independent activity of pupils on a new level, generating new personal senses in training, which lay the foundation for learning throughout life.

\section{MATERIALS AND METHODS}

We conducted and analyzed the study of students' educational and cognitive motivation dynamics in the process of distance education. The sample consisted of 103 intellectually gifted distance-learning students and 54 full-time students of the Regional Organizational and Methodological Center for Distance Education of Gifted Children, Rostov-on-Don, Russia. The age of participants is 13-18 years old, in school they are studying in grades 7-11. The average age is 15 years.

In the center of gifted students distance education, students are selected among the prize-winners of competitions and contests, that is, the students respond to the idea of intellectually gifted children, as defined by D. B. Bogoyavlenskaya.

The study was conducted in three stages: ascertaining (at the beginning of the academic year), forming (during the academic year) and control (at the end of the school year) experiment.

At the stage of the formative experiment, adolescents were trained in supplementary education programs for 7 months. In the content plan, the filling of distance learning programs for full-time associations coincides. The training was carried out by the same 
teachers.

The following methods were used in the study of adolescents:

- "Diagnostics of the educational motivation orientation" (by T. D. Dubovitskaya);

- "Focus on the acquisition of knowledge" (by E.P. Il'in, N.A. Kurdyukova);

- "Diagnosis of the school motivation type in high school students" (by E. Lepeshova);

- Test-questionnaire measuring the achievement motivation (modification of the A. Mehrabian test questionnaire (adaptation of M.Sh. Magomed-Eminov)).

A check of statistical significance was carried out using the Mann-Whitney U-criteria and the Pearson correlation analysis.

Gifted students were divided into three categories: two experimental groups: the first experimental group - regularly and systematically engaged with the use of active technologies; the second group is not systematically applying active technologies in distance education, the third group is the control one.

\section{RESULTS}

The results of the ascertaining experiment have shown that intellectually gifted distance learning students have a higher level of internal educational motivation, a high focus on acquiring knowledge. The study of the motivation for achieving in a sample as a whole shows the students' inclination for both distance form and full-time form to strive to avoid failures. Students in full-time education tend to be more successful at the beginning of training.

The motivation structure analysis at the stage of ascertaining experiment proves that all gifted students in the sample have the predominant motive for realizing the social necessity of education, while students of the distance form have the motive for self-realization on second place, the full-time students have the motive for the studying prestige in the family. Cognitive interest is on third place in all groups.

It is also interesting that the last place in the structure of motivation among all groups is occupied by "Extra-curricular school motivation", which characterizes intellectually gifted students as purposeful personalities, and the modern school as an institution of the education system, rather than entertainment or leisure. Also, the communication motive is fairly low, although it is higher in the group of full-time students than in the others.

Comparison of the indicators of educational and cognitive students motivation at the stage of ascertaining and control experiment allowed to see the dynamics in the motivational indicators of distance and full-time students (Table 1).

Table 1. Comparison the results of ascertaining and control experiment in the distance and full-time intellectually gifted students groups

\begin{tabular}{|c|c|c|c|c|c|c|c|}
\hline \multirow[t]{2}{*}{ 产 } & \multicolumn{2}{|c|}{$\begin{array}{c}\text { Level of } \\
\text { internal } \\
\text { learning motivation }\end{array}$} & \multirow{2}{*}{$\begin{array}{c}\begin{array}{c}\text { U - Mann- } \\
\text { Whitney criteria, } \\
\text { For } \mathbf{p} \leq 0.01\end{array} \\
\text { Stage } 1 \\
\end{array}$} & \multicolumn{2}{|c|}{$\begin{array}{l}\text { The severity of the } \\
\text { motivation for } \\
\text { knowledge acquisition }\end{array}$} & \multicolumn{2}{|c|}{$\begin{array}{c}\text { Directivity } \\
\text { motivation to } \\
\text { achieve }\end{array}$} \\
\hline & Stage 1 & Stage 3 & & Stage 2 & Stage 1 & Stage 1 & Stage 2 \\
\hline 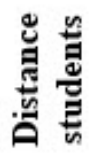 & 17,21 & 16,78 & 1048.5 & 10,43 & 10,50 & 142,15 & 141,46 \\
\hline 葛葛 & 16,82 & 17,53 & 757.5, & 9,82 & 9,33 & 145,47 & 143,13 \\
\hline
\end{tabular}

The level of internal educational motivation development (according to the methodology of T. D. Dubovitskaya) as a whole in students of distance education has decreased. The indicator of the level of internal teaching motivation development in full-time education students has grown. At the same time, the intensity of the motivation for the acquisition of knowledge (or cognitive motivation) as a whole has increased in distance learning students, and the number of students in full-time education has decreased.

As a result of the correlation analysis, a direct high significant correlation was found 
$(\mathrm{r}=0.45$, with $\rho \leq 0.01)$ between the parameters "level of development of internal educational motivation" (stage 2) and "the direction of motivation of achievement "in the sample of distance form students, as in full-time students group the correlation between these parameters is not observed ( $\rho$ does not reach the level of statistical significance).

The results of the change in motivational structures in different teenagers groups studying in distance education regularly (group A) using different methods and dealing occasionally via e-mail and assignments (group B) (Table 2) show that the level of development of internal learning motivation increased in students group A, that is, those students who actively mastered tasks that develop independent cognitive activity. In adolescents of group B, this indicator decreased. So the level of educational motivation is also associated with the teaching technologies used, along with cognitive motivation.

Table 2. Comparison the results of ascertaining and control experiment in the groups of distance and full-time intellectually gifted students

\begin{tabular}{|c|c|c|c|c|c|c|}
\hline \multirow[t]{2}{*}{ 旾 } & \multicolumn{2}{|c|}{$\begin{array}{c}\text { Level of } \\
\text { internal } \\
\text { learning motivation }\end{array}$} & \multicolumn{2}{|c|}{$\begin{array}{l}\text { The severity of the } \\
\text { motivation for } \\
\text { knowledge acquisition }\end{array}$} & \multicolumn{2}{|c|}{$\begin{array}{c}\text { Directivity } \\
\text { motivation to } \\
\text { achieve }\end{array}$} \\
\hline & $\begin{array}{c}\text { Stage } \\
1\end{array}$ & Stage 2 & Stage 1 & Stage 2 & Stage 1 & Stage 2 \\
\hline 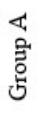 & 17,06 & 17,55 & 10,51 & 10,77 & 140,32 & 144 \\
\hline 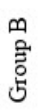 & 17,57 & 16,09 & 10,41 & 10,25 & 142,35 & 139,11 \\
\hline
\end{tabular}

The indicator of the motivation intensity for acquiring knowledge (cognitive motivation) among students in the first group also increased and among the students of group B decreased. Accordingly, the non-systematic initiation of independent activity and the transfer of excessive responsibility for tuition to students does not increase the educational and cognitive motivation.

The achievement motivation in group A has grown in the direction of motivation to achieve success. In the second group, this indicator declined. These patterns can be linked to the real success of teenagers in group A in training activities, participation and victories in olympiads and contests. As well as the growth of self-esteem of this category in connection with the development of skills and motivation for cognitive independence.

\section{DISCUSSIONS}

Analysis of the students' motivation structure in the process of the control experiment makes it possible to draw the following conclusions: the value of the indicator "Prestigiousness of studying in the family" in the distance education group has increased, this group also increased "Cognitive interest", that is the desire to learn new things; but the role of "Communication motivation" among distance education students decreased, which suggests that initially not very sociable young people with the introduction of distance education are even more isolated and reject communication.

The students of the additional education full-time form have increased the motivation to achieve.

The results of the experiment show a significant impact on the students of the full-time studying form the prestige of studying in the family, social approval by the parents, that is, parents rather determine the choice of the education forms and priorities of the adolescent's study, although the motive for comprehending social necessity, achievement and self-realization also occupies leading positions. That is, the students themselves are trying to realize themselves in teaching.

Individual motives: social necessity, achievement and self-realization, cognitive interest, - are dominated among the teenagers of the distance education form and only after that we see the motives connected with the family and parents. That is, students of distance learning are more independent in their choice and self-development.

So, with full-time education, the main emphasis is on the child development in the learning process, that is in the face-to-face meeting. In distance education the motivation development goes indirectly through the mediated interaction of the teacher and the student through the means of education, which means it goes through the subject of study, accordingly, the cognitive motivation develops. Thus the motivation is directed toward the subject.

The achievement motivation of all students (both the experimental and control groups) is reduced in the direction of motivation to avoid failure.

Thus, the competent and systematic application of technologies for the students in- 
dependent activity initiation in conditions of distance education has a positive effect on the educational, cognitive motivation and motivation of students' achievement, thereby developing and initiating the development of cognitive independence.

\section{CONCLUSIONS}

Theoretical analysis of the psychological foundations of the introduction of distance education systems, as well as practical conclusions of DE application, lead to the following generalizations:

1. Distance technologies - are a modern innovative tool for interactive education of students; implementing various models and means of education. The methodology of education with the use of distance technologies is changing, it becomes nonlinear.

2. The role of student development is important in the learning process. Initiation of independent activity as the training subject activity, which independently sets a goal, selects the methods of activity and independently compares the result and purpose of the activity, with the help of the teacher. Distance education has a high development potential - it is the developing opportunities in which a child grows. It is the application of various forms and technologies, based on deep psychological analysis, that helps to build the educational process in the educational aspect.

3. Along with other technologies, we proposed to refer different forms of distance education to different sense formation technologies and to realize them. Technologies of sense formation initiation can be presented in the form of developing technologies, interactive technologies, etc. Using different groups of technologies, oriented to different areas of mental development, different types of development, which are in essence different in form and content, we use human development resources in education. Sense-forming potential of technologies allows to deduce independent activity of pupils on a new level, generating new personal senses in training, which lay the foundation for learning throughout life.

4. An experimental study of the introduction of technologies for initiating independent activities in distance learning has shown that the internal educational motivation and other motivational students' mechanisms depend on the regularity and intensity of the initiating independent activity technology application, in particular, influences the level of internal learning motivation and the intensity of the acquiring knowledge motivation, motivation to achieve. Consequently, in the process of adolescents' independent cognitive activity the inner essence of cognitive motivation changes, the personal meaning of the teaching changes, other personal meanings are generated, which in turn affects the increase of competence in the self-education field.

5. The systematic cognitive activity of students influences the structure of educational motivation, so distance education students are dominated by individual motives of cognitive activity, so students of distance learning are more independent in their choice and direction of personality.

6. It is important to reduce the motivation of communication among distance learning students, both with the regular application of independent activity technologies and with the episodic. This trend is negative. That's why when developing a distance learning course, it is necessary to use a variety of technologies (interactive lectures, video materials, presentations, wiki-technologies, etc.), combining both independent activities and information and communication technologies (for example, videoconferences, chats and etc.), for the interaction of the teacher and student, and students among themselves. This trend as a basis for the success of distance education is noted by both competent teachers and successful students.

\section{Conflict of interests}

The authors declare no conflict of interest.

\section{ACKNOWLEDGMENTS}

The article was supported by the Russian Foundation for Basic Research RFBR (Project No. 18-29-22004 «Psychological and genetic studies of users' behavior predictors that determine the perception of Internet content of various informational orientation»).

\section{REFERENCES}

Abakumova I. V., Cuculyr A. M., Fomenko P. T. (2014). Sense didactics as a system embodiment of the General theory of meaning in the practice of the educational process. Российский психологический журнал, 11(3), 24-32. https:// doi.org/10.21702/rpj.2014.3.2

Bakaeva I. (2016). Psychological features of initiation of independent activity of adolescents in conditions of distance education, $P h D$ dissertation in 
psychology. Rostov-on-Don: Southern Federal University.166s. Retrieved from: https://hub. lib.sfedu.ru/storage/1/756716/23cef477-d73b4c77-ba5e-004214401b44/

Gromova T.V., Semochkina Yu.V. (2016). Application of active methods in the structure of distance learning. Science of the XXI century: current trends of development. 2-1. Pp. 7-10. Retrieved from: http://si.sseu.ru/sites/default/ files/2016/12/4ya_mezhdunarodnaya_zaochnaya_konferenciya_-_chast_1.pdf

Hood Cattaneo, K. (2017). Telling Active Learning Pedagogies Apart: from theory to practice. Journal of New Approaches in Educational Research. 6(2). https://doi.org/10.7821/naer.2017.7.237

Lebedeva M.B. (2010). Distance educational technologies: design and implementation of training courses. SPb.: Publishing house "BHV-Petersburg”, pp.336. Retrieved from: https://cyberleninka.ru/article/n/obrazovatelnye-tehnologiiterminologiya-i-so derzhanie

Ozhgibesova N., Chelyadinova O. (2014). Motivating academic students for foreign language learning by means of pedagogical techniques. World Applied Sciences Journal.IDOSI, 30 (5). 670-672. https://doi.org/10.5829/idosi. wasj.2014.30.05.14097

Park E., Song H. D. \& Hong A. J. (2018). The use of social networking services for classroom engagement? The effects of Facebook usage and the moderating role of user motivation. Active Learning in Higher Education, 4. https://doi. org/10.1177/1469787418809227

Reznik G. A., Ponomarenko Yu. S., Lyshchik O. V. (2016). Prospects for the development of distance educational technologies in a regional university. Education and science in the modern world. Innovation. 6(2). 29-43. Retrieved from: https://elibrary.ru/item.asp?id=27122659

Shuklina E.A. (2016). Massive open courses as a form of non-linear development of university education. Bulletin of Perm National Research Polytechnic University. Socio-economic sciences, 4, 79-93. Retrieved from: https://cyberleninka. $\mathrm{ru} /$ article/n/massive-open-online-courses-kakforma-nelineynogo-razvitiya-universitetskogoobrazovaniya

Silchenko L., Zubova T. (2017). About the practice of active learning methods. Scientific enquiry in the contemporary world: theoretical basics and innovative approach, 8-11. http://doi. org/10.15350/L_26/10/2

Uddin M. A. (2013). Individual differences of students studying in distance (a foreign literature review). Journal of Modern Foreign Psychology, 3, 104-121. Retrieved from: http://psyjournals. $\mathrm{ru} / \mathrm{en} / \mathrm{jmfp} / 2013 / \mathrm{n} 3 / 63932 . \mathrm{shtml}$ 